\title{
Virilizing Ovarian Leydig Cell Tumor with Multiple Non-Functional Endocrine Neoplasias: A Case Report
}

\author{
Yining Xie ${ }^{1 *}$, Shan Zhong1, Qijing Zhou², Zhiheng Huang ${ }^{3,4}$, Xiaoxiao Song1", Xiaohong Xu${ }^{1 \#}$ \\ ${ }^{1}$ Department of Endocrine and Metabolic Diseases, The Second Affiliated Hospital, Zhejiang University School of Medicine, \\ Hangzhou, China \\ ${ }^{2}$ Department of Radiology, The Second Affiliated Hospital, Zhejiang University School of Medicine, Hangzhou, China \\ ${ }^{3}$ Department of Surgical Oncology, The Second Affiliated Hospital, Zhejiang University School of Medicine, Hangzhou, \\ China \\ ${ }^{4}$ Department of Otorhinolaryngology, The Second Affiliated Hospital, Zhejiang University School of Medicine, Hangzhou, \\ China \\ Email: *xuxiaoh@zju.edu.cn, xsong103@zju.edu.cn
}

How to cite this paper: Xie, Y.N., Zhong, S., Zhou, Q.J., Huang, Z.H., Song, X.X. and Xu, X.H. (2019) P Virilizing Ovarian Leydig Cell Tumor with Multiple Non-Functional Endocrine Neoplasias: A Case Report. International Journal of Clinical Medicine, 10, 306-315.

https://doi.org/10.4236/ijcm.2019.104023

Received: March 10, 2019

Accepted: April 22, 2019

Published: April 25, 2019

Copyright $\odot 2019$ by author(s) and Scientific Research Publishing Inc. This work is licensed under the Creative Commons Attribution International License (CC BY 4.0).

http://creativecommons.org/licenses/by/4.0/

cC) (i) Open Access

\begin{abstract}
Ovarian Leydig cell tumor, a sub-type of ovarian steroid cell tumor, accounts for less than $0.1 \%$ of all ovarian tumors. It can affect women of any age group but is most common in postmenopausal women. We here report a case of virilizing ovarian Leydig cell tumor with multiple non-functional endocrine neoplasias (pituitary and adrenal adenomas) in a 48 -year-old woman. She first presented with sub-abdominal pain and hirsutism since menopause three years ago. Subsequently, she had slight facial acne, voice deepening, breast atrophy, and a prominent Adam's apple. Her hormone profile showed an elevated level of testosterone, high free androgen index, low levels of luteinizing hormone and follicle stimulating hormone, and normal levels of random cortisol, androstenedione, 17-hydroxyprogesterone and dehydroepiandrosterone sulfate. A pelvic enhanced magnetic resonance imaging (MRI) scan showed nodules in the right ovary, and a pituitary enhanced MRI revealed a microadenoma. An enhanced computerized tomography scan of the adrenal gland revealed left adrenal nodules, possibly adenomas. After a right cystectomy and right fallopian tube resection, her testosterone level declined to $0.38 \mathrm{nmol} / \mathrm{L}$ and the symptoms associated with hyperandrogenism improved. This is a rare case of virilizing ovarian Leydig cell tumor with multiple non-functional endocrine neoplasias. We believe our findings will be helpful in the clinical diagnosis and treatment of hyperandrogenism.
\end{abstract}

"Xiaohong Xu and Xiaoxiao Song contributed equally to this work. 


\section{Keywords}

Leydig Cell Tumor, Ovary, Adrenal Adenomas, Hyperandrogenism

\section{Introduction}

Leydig cell tumor is a rare subtype of the ovarian sex cord-stromal tumors, composed of Leydig cells [1]. It accounts for less than $0.1 \%$ of all the ovarian tumors. The clinical features of Leydig cell tumors are associated with hormone levels and mass occupancy effects. It is characterized by a wide range of age of onset, low malignancy rate, and good prognosis after surgical resection. Ovarian Leydig cell tumors often occur in postmenopausal women. Based on existing case reports, Leydig cell ovarian tumors accompanied by an adrenal adenoma can be difficult to diagnose [2]. We here report a unique case of virilizing ovarian cell tumor accompanied by multiple non-functional endocrine neoplasias. The patient had non-functional pituitary microadenomas as well as adrenal adenomas. She also had a thyroid adenoma which was resected 30 years ago. This is a rare case of an ovarian Leydig cell tumor with multiple non-functional endocrine neoplasias.

\section{Case Report}

A 48-year-old woman visited a local hospital for sub-abdominal pain and hirsutism since she had menopause three years ago. She was pregnant only once and gave birth to one child. The initial laboratory findings showed an elevated testosterone level (value not available), but she did not receive any treatment. She had laser hair removal performed several times for excessive hair growth. She went to the hospital for a re-examination two months ago, and the hematological tests revealed a high level of testosterone ( $>35 \mathrm{nmol} / \mathrm{l})$. Additionally, a pituitary enhanced magnetic resonance imaging (MRI) showed microadenomas (size was not marked). She then came to our hospital for treatment.

The patient had undergone a partial left thyroidectomy for a thyroid adenoma, 30 years ago and was receiving a long-term oral administration of Euthyrox (75 $\mu \mathrm{g}$ QD). Uterine myomectomy was performed more than 10 years ago.She had achieved menopause at the age of 45 with no postmenopausal bleeding. She had a normal menstrual history before menopause no history of hypertension and diabetes. She did not smoke or drink. A physical examination revealed the following: weight: $60 \mathrm{~kg}$ and body mass index (BMI): $22.4 \mathrm{~kg} / \mathrm{m}^{2}$. She presented with normal hair distribution because of the laser hair removal. However, she had slight facial acne, voice deepening, breast atrophy, and a prominent Adam's apple.

The hormone profile of the patient revealed the following: testosterone: 29.42 $\mathrm{nmol} / \mathrm{L}$ (reference value $<2.5$ ), free androgen index: $79.63(0.3-9.6)$, luteinizing hormone (LH): $0.86 \mathrm{IU} / \mathrm{L}$ (11.30 - 39.80), follicle stimulating hormone (FSH): 
$5.02 \mathrm{mIU} / \mathrm{L}$ (21.7 - 153), estradiol E2: $203.5 \mathrm{pmol} / \mathrm{L}$ (post menopause, <110), thyroid peroxidase antibody: $>1000 \mathrm{IU} / \mathrm{ml}(<5.61)$, thyroglobulin antibody: 14.7 (<4.11), and thyroglobulin: $129.20 \mu \mathrm{g} / \mathrm{L}$ (3.5 - 77.0). Random cortisol, androstenedione, 17-hydroxyprogesterone and dehydroepiandrosterone sulphate (DHEA-S) concentrations were within the normal range.

A pituitary enhanced MRI revealed abnormal nodular signals in the posterior pituitary suggestive of microadenomas or Rathke cysts (Figure 1). An enhanced computerized tomography scan of the adrenal gland showed left adrenal nodules which were diagnosed as adenomas (Figure 2). Transvaginal B-mode ultrasonography showed no significant abnormalities in the ovaries.

A medium dose dexamethasone suppression test resulted in significant inhibition of cortisol and adrenocorticotropic hormone (ACTH), while just a $4 \%$ decrease in the serum levels of testosterone (baseline level $37.44 \mathrm{nmol} / \mathrm{L}$, after test $35.97 \mathrm{nmol} / \mathrm{L}$ ), suggesting that the hyperandrogenism may not be due to the adrenal gland. To further clarify whether the high concentration of testosterone originated from the proliferative left adrenal gland and to determine the location of the lesion, bilateral adrenal venous blood sampling was performed. However, the adrenal venous blood collection was unsuccessful.

A pelvic enhanced MRI scan showed a right ovarian nodule $(14.3 * 28.4 \mathrm{~mm})$, and multiple uterine fibroids (Figure 3). To detect other possible neoplasms and explore the source of the abnormal testosterone secretion, she had a whole-body positron emission tomography (PET) scan. The findings revealed a low-density lesion $(16.6 * 20.8 * 24.8 \mathrm{~mm})$ in the right ovary, bilateral thyroid nodules and possibly a left adrenal adenoma. Based on the above results, the hyperandrogenism appeared to be arising from the right ovary.

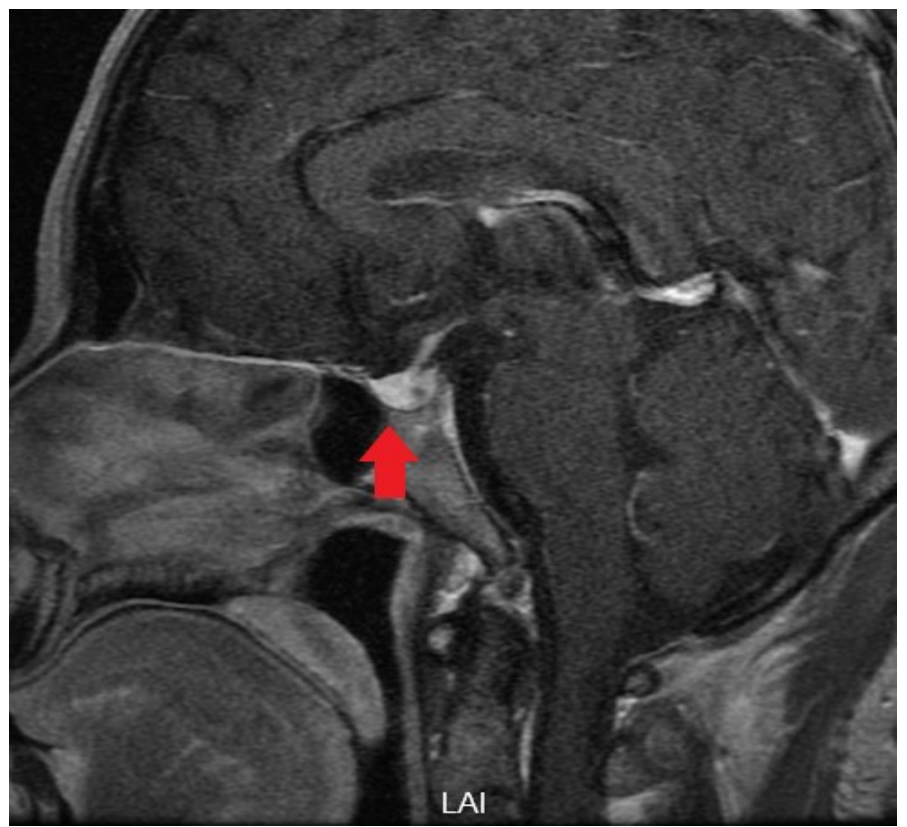

Figure 1. Pituitary MRI enhancement findings (sagittal): Hypointense nodules between the anterior and posterior pituitary glands. 

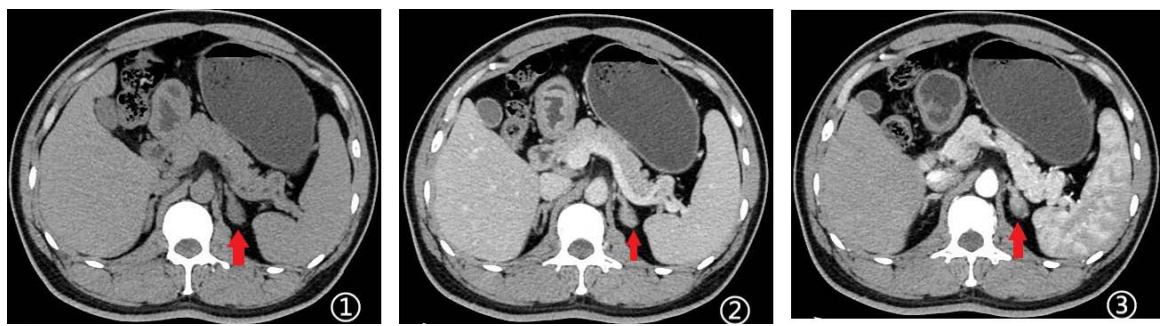

Figure 2. Adrenal CT enhancement findings: (1) CT scan of the adrenal gland, Adrenal CT enhancement in the (2) venous, and (3) arterial phases.

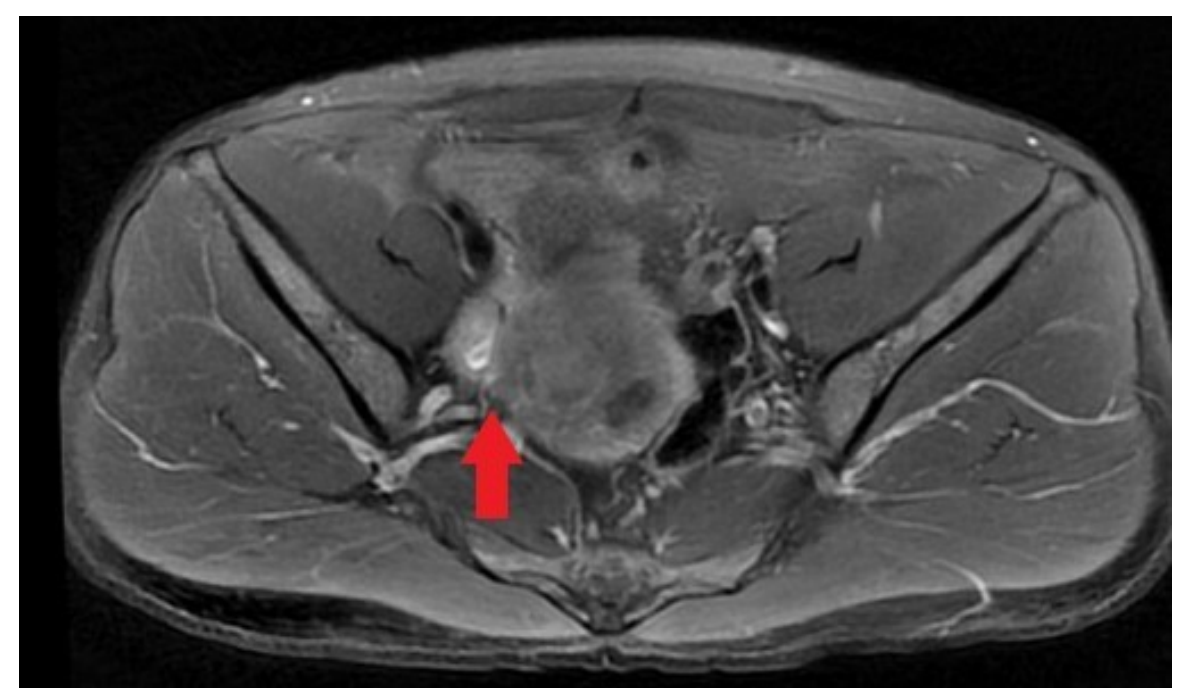

Figure 3. Pelvic MRI findings (T2W2): In the right appendix area, is a lesion with unclear local uterine boundary, and slightly high signal intensity.

The patient went to another hospital for surgical treatment on October 25, 2017. She had a right cystectomy, right fallopian tube resection, and adenomyoma debridement, but no adjuvant chemotherapy. During surgery, the right ovary was found to be enlarged with a cystic mass of $2^{\star} 2 \mathrm{~cm}$. The postoperative pathological evaluation of the right ovarian cyst indicated an ovarian Leydig cell tumor combined with an inclusion cyst. A sex hormone test on the fourth day after surgery reported a significant decrease in testosterone level $(0.38 \mathrm{nmol} / \mathrm{L})$, increase in LH (13.49 IU/L) and FSH (23.5 IU/L) to normal levels, and normal lev$\mathrm{el}$ of the concord hormone $(0.19 \mathrm{ng} / \mathrm{ml})$. After 14 months of surgery, the serum testosterone level has been normal, and the signs and symptoms of hyperandrogenism including the voice change, facial acne, breast atrophy, and Adam's apple have all improved.

\section{Discussion}

Hyperandrogenism and hirsutism are mostly related to polycystic ovary syndrome (PCOS). However, less than $5 \%$ of the cases are caused by androgen-secreting tumors of either adrenal or ovarian origin [3]. Serum testosterone levels are typically used to assess androgen levels. Androgen-producing tumors 
should be considered when patients present with rapid progression of signs and symptoms of hyperandrogenism, especially when the testosterone levels are more than three times the upper reference limit [4]. DHEA-S is a marker of adrenal androgen production, and serum DHEA-S levels greater than 16 umoL usually point to an androgen-secreting adrenal tumor [5]. In Leydig cell tumors, serum testosterone levels are expected to be slightly elevated [6] or highly elevated as seen in our case. The patient, this case, was suspected of having androgen-secreting neoplasms due to the very high level of testosterone (37.44 $\mathrm{nmol} / \mathrm{l})$. The normal transvaginal ultrasonography findings and the adrenal adenoma led us to consider adrenal-derived hyperandrogenism. However, the normal serum level of DHEA-S and the PET scan results ruled out the adrenal cause.

It is noteworthy that in this case dexamethasone was used to exclude congenital adrenal hyperplasia (CAH), rather than the ACTH excitation test, which is commonly used worldwide. CAH is a group of autosomal recessive hereditary diseases [7] that affects the adrenal glands. It is caused due to the deficiency of an enzyme, leading to a partial or complete block of cortisol synthesis. This, in turn, results in an increase in corticotropin-releasing hormone (CRH) secreted by the hypothalamus and ACTH secreted by the pituitary, which stimulates adrenocortical hyperplasia, thereby resulting in varying degrees of adrenocortical dysfunction. The most common cause of $\mathrm{CAH}$ is 21 hydroxylase deficiency (21OHD) [7], followed by 11 beta-hydroxylase deficiency [8]. Rapid ACTH excitation test is recommended for differential diagnosis in clinical practice [9], though it is rarely used in China due to the lack of ACTH drug sources. Dexamethasone inhibits cortisol and adrenal-derived androgen secretion by inhibiting the pituitary ACTH secretion. Therefore, since the 1980s, China has been using a functional test to differentiate androgen sources by giving moderate doses of dexamethasone [10], to detect changes in levels of ACTH, 17-OHP and total testosterone.

Among the ovarian androgen-secreting neoplasms, steroid cell tumors are quite rare [11]. Ovarian Leydig cell tumor, a sub-type of the ovarian steroid cell tumors, accounts for less than $0.1 \%$ of all ovarian tumors. It can affect women of any age group, but is most common in postmenopausal women [12] [13]. Over $75 \%$ of the cases of ovarian Leydig cell tumors present with severe hyperandrogenism characterized by hirsutism, secondary amenorrhea, virilization, and a small number of tumors with high estrogen or non-endocrine function. Likewise, nearly $75 \%$ of the cases with severe hyperandrogenism involve Leydig cell tumors [14]. More than 95\% of the ovarian Leydig cell tumors are unilateral, and only 7 bilateral cases have been reported. Most of these tumors are benign and smaller than $4 \mathrm{~cm}$ in size [15]. Surgical removal of these tumors results in significant improvement in the symptoms and has an excellent prognosis.

The strategies for managing Leydig cell tumors include surgery and adjuvant chemotherapy (usually used in malignant tumors). The type of surgery which includes unilateral (for fertility preservation), bilateral salpingo-oophorectomy or 
cystectomy, usually depends on the patient's age, fertility requirements, and the nature of the tumor. Conservative and fertility-sparing surgery is especially recommended in younger patients or patients without children.

Due to the lack of clear diagnostic criteria, the diagnosis of ovarian Leydig cell tumors still remains challenging and cannot be done without surgery. Moreover, due to their small size and density, these tumors are usually invisible on ultrasonography and CT. When accompanied by an adrenal adenoma, the diagnosis becomes even more difficult. Though hyperandrogenism due to an adrenal adenoma is not uncommon, it can be very difficult to detect the origin of the hyperandrogenism, especially with high levels of cortisol [2]. Ovarian and adrenal venous sampling can be performed, but both of them require advanced technology, and the success rate is low.

\section{Diagnostic Process}

Based on this case, we reviewed the existing literature and summarized what is known about the etiology and diagnosis of hyperandrogenism (Figure 4).

The main clinical manifestations of hyperandrogenism include hirsutism, acne, androgenic alopecia, masculinization and some special manifestations [16] [17]. Clinically, the etiology of hyperandrogenism is complex, and PCOS is the most common functional etiology [18]. The organic etiologies mainly include congenital adrenocortical hyperplasia, androgen-secreting tumors, and abnormal sexual differentiation [16]. Therefore, the key to the diagnosis of hyperandrogenism is to determine the source and etiology of androgen production [19]. If the patient had a previous history of abnormal menstruation, the lesion might have originated from the ovary [17]. On the other hand, if the patient developed hirsutism and masculinization in a short time, androgen-producing adrenal or ovarian tumors should be considered [3]. Though the main manifestation of idiopathic hirsutism includes excessive hair growth and normal ovulation, the related medication history and stress factors such as menopause and pregnancy also help in making the diagnosis [5]. Based on the patient's medical history, physical examination, B-mode ultrasound, CT and MRI, large ovarian, adrenal or pituitary tumors can be excluded, which can then provide diagnostic clues for unexplained hyperandrogenism [20]. When the tumor is small and concealed, it is easy to miss in B-mode ultrasound and other imaging examinations. If the patient suffered from both adrenal mass and ovarian mass, location diagnosis is very difficult [21]. Adrenal venous blood collection or ovarian venous blood collection technology is of critical significance in the differential diagnosis of androgen source. Determination of hormone levels is essential for the diagnosis of hyperandrogenism [22]. Increase in different kinds of androgens may indicate the presence of lesions and therefore, can provide important leads for clinical diagnosis. Elevated levels of testosterone and LH/FSH $>2$ are suggestive of PCOS. Adrenal tumors are characterized by marked elevation of testosterone with DHEA-S $>16 \mu \mathrm{mol} / \mathrm{L}$. In cases of congenital adrenocortical hyperplasia, 


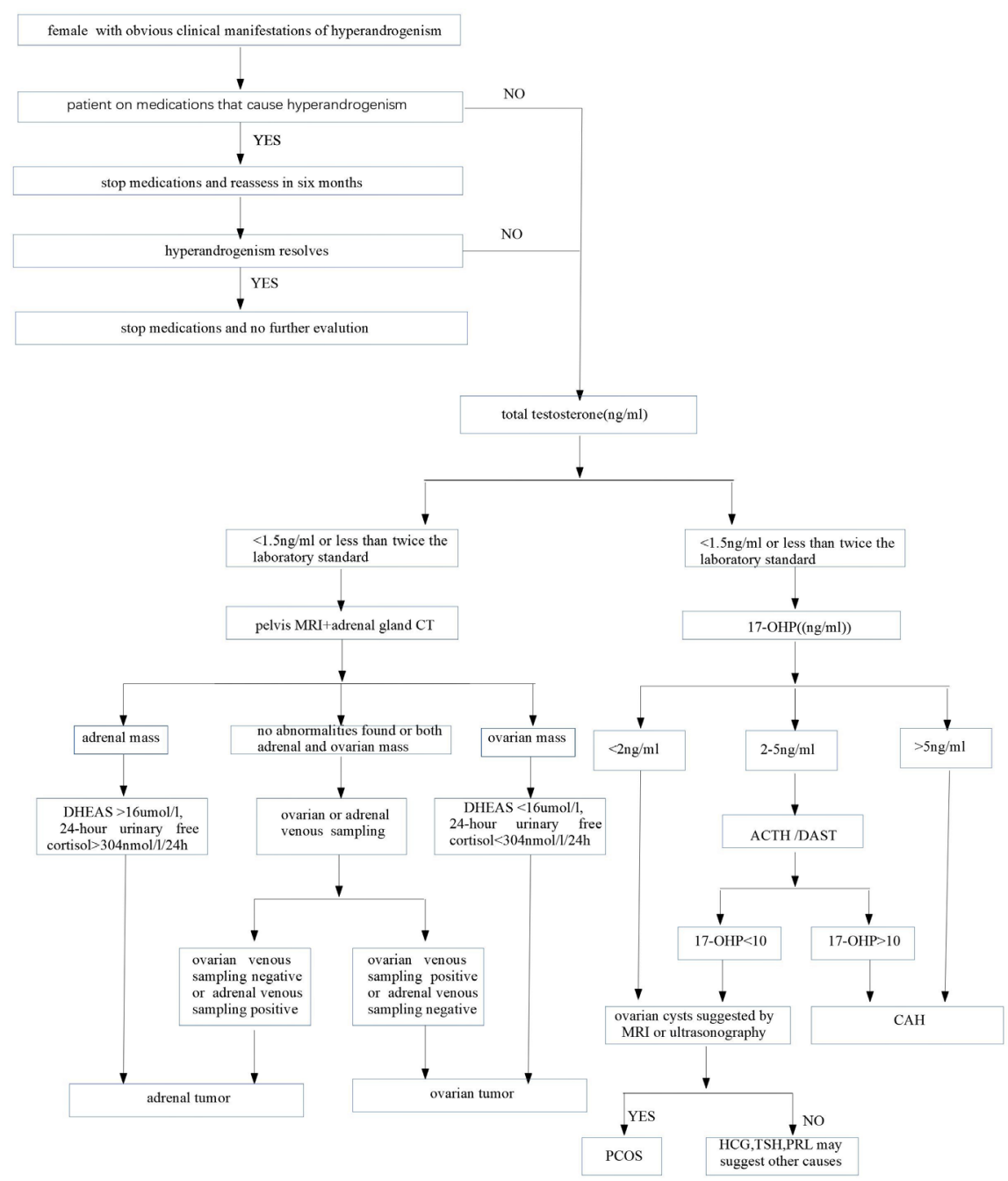

Figure 4. Diagnostic process of hyperandrogenism.

testosterone and 17-OHP are elevated, or markedly elevated after adrenocorticotropic stimulation [23] [24]. The elevation of dihydrotestosterone with low testosterone suggests the possibility of idiopathic hirsutism [25] [26]. When testosterone and cortisol levels are elevated simultaneously, adrenocortical hyperfunction should be evaluated using the dexamethasone inhibition test [27] [28] [29].

\section{Conclusions}

In conclusion, we report a case of ovarian Leydig cell tumor with multiple non-functional endocrine neoplasms in post-menopausal women, characterized by hirsutism. This is a rare case of a Leydig cell tumor with multiple non-functional endocrine neoplasms, though Leydig cell tumors accompanied by adrenal adenomas are not uncommon.

Although rare and difficult to diagnose, ovarian Leydig cell tumors should be considered in cases with severe hyperandrogenism and hirsutism after the exclu- 
sion of adrenal-derived hyperandrogenism, especially in postmenopausal women. In such patients with hirsutism and significantly elevated testosterone level, an oophorectomy should be considered after the exclusion of adrenal causes. In our case, surgical intervention confirmed the final diagnosis of a Leydig cell tumor. As expected, following surgery, the hormone levels returned to normal and clinical symptoms of hyperandrogenism improved.

\section{Funding}

This work was supported by grant from Science Technology Department of Zhejiang Province of China (grant number 2012C33054 to XXH), grant from Zhejiang Provincial Medical and Health Technology Project (grant number 2013KYA089 to XXS). The funders had no role in report design, data collection and analysis, decision to publish, or preparation of the manuscript.

\section{Conflicts of Interest}

The authors declare no conflicts of interest regarding the publication of this paper.

\section{References}

[1] Youssef, A., Ben Ghezala, M., Oueslati, A., Agrebi, W. and Oueslati, H. (2006) Sertoli-Leydig Cell Tumor of the Ovary. La Tunisie Médicale, 84, 209-211.

[2] Diab, D.L., Faiman, C., Siperstein, A.E., Grossman, W.F., Rabinowitz, L.O. and Hamrahian, A.H. (2008) Virilizing Ovarian Leydig Cell Tumor in a Woman with Subclinical Cushing Syndrome. Endocrine Practice, 14, 358-361. https://doi.org/10.4158/EP.14.3.358

[3] Rosenfield, R.L. (2005) Clinical Practice. Hirsutism. The New England Journal of Medicine, 353, 2578-2588. https://doi.org/10.1056/NEJMcp033496

[4] Glintborg, D., Altinok, M.L., Petersen, K.R. and Ravn, P. (2015) Total Testosterone Levels Are often more than Three Times Elevated in Patients with Androgen-Secreting Tumours. BMJ Case Reports, 2015, bcr2014204797. https://doi.org/10.1136/bcr-2014-204797

[5] Practice Committee of the American Society for Reproductive Medicine (2006) The Evaluation and Treatment of Androgen Excess. Fertility and Sterility, 86, S241-247. https://doi.org/10.1016/j.fertnstert.2006.08.042

[6] Sherf, S. and Martinez, D. (2017) Leydig Cell Tumor in the Post-Menopausal Woman: Case Report and Literature Review. Acta BioMedica, 87, 310-313.

[7] Schlosser, R., Schafer, J. and Kaufmann, R. (2012) Heterozygous 21-Hydroxylasedeficiency as a Cause of Hyperandrogenism. JDDG: Journal der Deutschen Dermatologischen Gesellschaft, 10, 841-842. https://doi.org/10.1111/j.1610-0387.2012.08013.x

[8] Turcu, A.F. and Auchus, R.J. (2015) The Next 150 Years of Congenital Adrenal Hyperplasia. The Journal of Steroid Biochemistry and Molecular Biology, 153, 63-71. https://doi.org/10.1016/j.jsbmb.2015.05.013

[9] Speiser, P.W., Azziz, R., Baskin, L.S., Ghizzoni, L., Hensle, T.W., Merke, D.P., Meyer-Bahlburg, H.F., Miller, W.L., Montori, V.M., Oberfield, S.E., Ritzen, M. and White, P.C. (2010) Congenital Adrenal Hyperplasia Due to Steroid 21-Hydroxylase Deficiency: An Endocrine Society Clinical Practice Guideline. The Journal of Clinical Endocrinology \& Metabolism, 95, 4133-4160. 
https://doi.org/10.1210/jc.2009-2631

[10] Dai, H., Lu, L., Xing, X.-P., Wang, L.-J., Duan, L., Jiang, J., Zhu, L., Li, M., Song, A.-L., Yang, G.-H., Yu, Q., Tian, Q.-J., Zhou, Y.-Z. and Lu, Z.-L. (2018) Efficacy of Medium Dose Dexamethasone Androgen Suppression Test in the Diagnosis of Female Hyperandrogenism. National Medical Journal of China, 98, 2073-2077.

[11] Swain, J., Sharma, S., Prakash, V., Agrawal, N.K. and Singh, S.K. (2013) Steroid Cell Tumor: A Rare Cause of Hirsutism in a Female. Endocrinology, Diabetes \& Metabolism Case Reports, 2013, Article ID: 13-0030.

https://doi.org/10.1530/EDM-13-0030

[12] Kozan, P., Chalasani, S., Handelsman, D.J., Pike, A.H. and Crawford, B.A. (2014) A Leydig Cell Tumor of the Ovary Resulting in Extreme Hyperandrogenism, Erythrocytosis, and Recurrent Pulmonary Embolism. The Journal of Clinical Endocrinology \& Metabolism, 99, 12-17. https://doi.org/10.1210/jc.2013-3108

[13] Souto, S.B., Baptista, P.V., Braga, D.C. and Carvalho, D. (2014) Ovarian Leydig Cell Tumor in a Post-Menopausal Patient with Severe Hyperandrogenism. Arquivos Brasileiros de Endocrinologia \& Metabologia, 58, 68-75. https://doi.org/10.1590/0004-2730000002461

[14] Yetkin, D.O., Demirsoy, E.T. and Kadioglu, P. (2011) Pure Leydig Cell Tumour of the Ovary in a Post-Menopausal Patient with Severe Hyperandrogenism and Erythrocytosis. Gynecological Endocrinology, 27, 237-240. https://doi.org/10.3109/09513590.2010.490611

[15] Nardo, L.G., Ray, D.W., Laing, I., Williams, C., McVey, R.J. and Seif, M.W. (2005) Ovarian Leydig Cell Tumor in a Peri-Menopausal Woman with Severe Hyperandrogenism and Virilization. Gynecological Endocrinology, 21, 238-241. https://doi.org/10.1080/09513590500369005

[16] Elhassan, Y.S., Idkowiak, J., Smith, K., Asia, M., Gleeson, H., Webster, R., Arlt, W. and O'Reilly, M.W. (2018) Causes, Patterns, and Severity of Androgen Excess in 1205 Consecutively Recruited Women. The Journal of Clinical Endocrinology \& Metabolism, 103, 1214-1223. https://doi.org/10.1210/jc.2017-02426

[17] Markopoulos, M.C., Kassi, E., Alexandraki, K.I., Mastorakos, G. and Kaltsas, G. (2015) Hyperandrogenism after Menopause. European Journal of Endocrinology, 172, R79-R91. https://doi.org/10.1530/EJE-14-0468

[18] Dennedy, M.C., Smith, D., O’Shea, D. and McKenna, T.J. (2010) Investigation of Patients with Atypical or Severe Hyperandrogenaemia Including Androgen-Secreting Ovarian Teratoma. European Journal of Endocrinology, 162, 213-220. https://doi.org/10.1530/EJE-09-0576

[19] Yildiz, B.O. (2006) Diagnosis of Hyperandrogenism: Clinical Criteria. Best Practice \& Research Clinical Endocrinology \& Metabolism, 20, 167-176. https://doi.org/10.1016/j.beem.2006.02.004

[20] Fanta, M., Fischerova, D., Indrielle-Kelly, T., Koliba, P., Zdenkova, A., Burgetova, A. and Vrbikova, J. (2018) Diagnostic Pitfalls in Ovarian Androgen-Secreting (Leydig Cell) Tumours: Case Series. Journal of Obstetrics and Gynaecology, 14, 1-6.

[21] Levens, E.D., Whitcomb, B.W., Csokmay, J.M. and Nieman, L.K. (2009) Selective Venous Sampling for Androgen-Producing Ovarian Pathology. Clinical endocrinology, 70, 606-614. https://doi.org/10.1111/j.1365-2265.2008.03389.x

[22] Peigne, M., Villers-Capelle, A., Robin, G. and Dewailly, D. (2013) Hyperandrogenism in Women. La Presse Médicale, 42, 1487-1499.

[23] Smeets, E.E., Span, P.N., van Herwaarden, A.E., Wevers, R.A., Hermus, A.R., 
Sweep, F.C. and Claahsen-van der Grinten, H.L.(2015) Molecular Characterization of Testicular Adrenal Rest Tumors in Congenital Adrenal Hyperplasia: Lesions with Both Adrenocortical and Leydig Cell Features. The Journal of Clinical Endocrinology \& Metabolism, 100, E524-E530. https://doi.org/10.1210/jc.2014-2036

[24] Hishiki, T., Kazukawa, I., Saito, T., Terui, K., Mitsunaga, T., Nakata, M., Matsuura, G., Minagawa, M., Kohno, Y. and Yoshida, H. (2008) Diagnosis of Adrenocortical Tumor in a Neonate by Detection of Elevated Blood 17-Hydroxyprogesterone measured as a Routine Neonatal Screening for Congenital Adrenal Hyperplasia: A Case Report. Journal of Pediatric Surgery, 43, e19-e22.

https://doi.org/10.1016/j.jpedsurg.2008.05.023

[25] Erem, C. (2013) Update on Idiopathic Hirsutism: Diagnosis and Treatment. Acta Clinica Belgica, 68, 268-274. https://doi.org/10.2143/ACB.3267

[26] Bonakdaran, S., Kiafar, B. and Barazandeh, A.F. (2016) Evaluation of Insulin Resistance in Idiopathic Hirsutism Compared with Polycystic Ovary Syndrome Patients and Healthy Individuals. Australasian Journal of Dermatology, 57, e1-e4. https://doi.org/10.1111/ajd.12276

[27] Severi, S., Galli, A. and Forleo, R. (1967) Free Testosterone and Epitestosterone and Glucosiduronates in the Urine of Females. 3. Test of Adrenal Inhibition with Dexamethasone. Folia endocrinologica, 20, 66-80.

[28] Pascale, M.M., Pugeat, M., Roberts, M., Rousset, H., Dechaud, H., Dutrieuxberger, N. and Tourniaire, J. (1994) Androgen Suppressive Effect of Gnrh Agonist in Ovarian Hyperthecosis and Virilizing Tumors. Clinical Endocrinology, 41, 571-576. https://doi.org/10.1111/j.1365-2265.1994.tb01820.x

[29] Pecori Giraldi, F., Pivonello, R., Ambrogio, A.G., De Martino, M.C., De Martin, M., Scacchi, M., Colao, A., Toja, P.M., Lombardi, G. and Cavagnini, F. (2007) The Dexamethasone-Suppressed Corticotropin-Releasing Hormone Stimulation Test and the Desmopressin Test to Distinguish Cushing's Syndrome from Pseudo-Cushing's States. Clinical Endocrinology, 66, 251-257.

https://doi.org/10.1111/j.1365-2265.2006.02717.x 